Original Research Paper

\title{
Mechanically Stimulated Osteoblast Cells Growth
}

\author{
${ }^{1}$ Raffaella Aversa, ${ }^{1}$ Antonio Apicella, ${ }^{1}$ Francesco Tamburrino and ${ }^{2}$ Florian Ion Tiberiu Petrescu \\ ${ }^{1}$ Advanced Material Lab, Department of Architecture and Industrial Design, \\ Second University of Naples, 81031 Aversa (CE), Italy \\ ${ }^{2}$ ARoTMM-IFToMM, Bucharest Polytechnic University, Bucharest, (CE), Romania
}

\author{
Article history \\ Received: 23-5-2018 \\ Revised: 05-6-2018 \\ Accepted: 12-6-2018 \\ Corresponding Author: \\ Florian Ion Tiberiu Petrescu \\ ARoTMM-IFToMM, Bucharest \\ Polytechnic University, \\ Bucharest, (CE), Romania \\ Email: scipub02@gmail.com
}

Abstract: The bones need to be built and then permanently restored to keep them functioning properly. Considering the multiple bone functions, their vitality is essential both to maintain the body and move it and to maintain its health and vigor. When most bones begin to age and have no vital function, the man also begins to age, lose water, minerals, electrolytes, energy, food. We can firmly affirm that healthy bones maintain an excellent health of the human body. All of the bones in the young have the role of deposit, water, electrolyte, minerals, energy, substances necessary for the growth and repair of human cells and organs, a part (red marrow) that permanently produces the vital blood for the organism with the three vital cell types: red (body oxygenation), white (which defends the body) and platelets (it clogs the blood when a wound appears). More recently, it is also known that the red marrow is responsible for the stem cells production, cells which are so necessary to the body because they can adapt to anywhere in the body in any organ, rapidly generating the various types of cells needed. In the bones of the young and most of the adult, all these functionalities appear, so that when an accident requires a human operation it is good to resort to mild and specialized interventions so that the bone in question can quickly recover all features. Otherwise, the body of that person has a major future health and integrity problem, as is the case with older people or those with serious bone diseases. The research develops and tests new hybrid biomimetic materials that work as mechanically stimulating "scaffolds" to promote early regeneration in implanted bone healing phases. A biomimetic nanostructured osteoconductive material coated apparatus is presented. Bioinspired approaches to materials and templated growth of hybrid networks using self-assembled hybrid organicinorganic interfaces are finalized to extend the use of hybrids in the medical field. Combined in vivo, in vitro and computer-aided simulations have been carried out. Such multidisciplinary approach allowed us to explore many novel ideas in modeling, design and fabrication of new nanostructured biomaterials and scaffolds with enhanced functionality and improved interaction with $\mathrm{OB}$ cells. In vivo tests of Titanium screw implanted in rabbit, tibiae have shown that mechanical stimulation was induced by the presence of bioactive hybrid perimplantar scaffold resulting in a differentiation and development of mesenchymal tissues. In order to investigate the relationship between bone growth and applied mechanical loading (strain), a piezoelectrically driven cantilever and a computercontrolled apparatus for "in vitro" tests has been developed and presented.

Keywords: Biomechanics, Biomimetics, Hybrid Nanostructured Biomaterials, Piezoelectric, Biomaterials, Bone, Cartilage, Ossification, Osteoblasts, Osteocytes, Bones Early Regeneration 


\section{Introduction}

Anatomy is a branch of biology and implicit medicine that studies the structure of living beings. The term has a general character that includes the anatomy of plants, animals and, of course, man.

Human anatomy is the fundamental discipline of human medicine. It is taught at an early stage in the preparation of any physician, even from faculty banks and thoroughly detailed in the body or plastic moldings.

The bone system in an adult body consists of 206 individual bones. These bones are arranged in two main categories: the axial skeleton and the appendicular skeleton. The axial skeleton runs along the median axis of the body and consists of 80 bones in the following regions:

- Skull

- Hyoid bone

- Bones for hearing aids

- Ribs

- Stern

- Spine

The skull is composed of 22 bones, which are merged except for the mandible. These 21 fused bones are separated in children to allow the skull and brain to grow, but they will merge to provide increased resistance and protection as it grows. The mandible remains a bone of the jaw and forms alongside the temporal bone, the only mobile joint in the skull. The bones in the upper part of the skull protect the brain from damage. The bones of the lower and anterior skull are known as facial bones and support the eyes, nose and mouth.

Hypoid bone and auditory oscillators. The hioid bone is a small U-shaped bone and is located in the lower mandible. The hioid bone is the only bone in the body that does not form a joint with another bone - this is a floating bone. The function of the hypoid bone is to help maintain the trachea open and to form a bone connection for the muscles of the tongue. This bone is often associated with the skull, but it is not part of it. The hioid bone just anchors some muscles.

The hammer, the scar and the anvil - collectively known as auditory oscillators - are the smallest bones in the body. They are found in a small cavity inside the temporal bone and serve to transmit and amplify the sound from the eardrum to the inner ear.

Spine 33-35 vertebrae form the backbone of the human body. They are named by region:

- Cervical (neck) - 7 vertebrae

- Thoracic (chest) - 12 vertebrae

- Lombara (lower back) - 5 vertebrae

- Sacrum - 5 vertebrates merged

- Coccis (nocturnal) - 3-5 vertebrae fused
With the exception of vertebrae in the sacrum and coccis region, each vertebra is named according to the first letter of the region and its position along the upperlower axis. For example, the upper thoracic vertebra is called $\mathrm{T} 1$ and the lower thoracic is called T12.

\section{Rib and Stern}

The sternum is a knife-shaped bone located along the median line in the anterior part of the thoracic region of the skeleton. The sternum connects to the ribs through thin cartilage strips called costal cartilage. The sternum is a very resistant bone and it takes a very strong kick to break it.

There are 12 pairs of ribs, which, together with the shape of the sternum, form the chest box. The first seven ribs are known as "true ribs" because they articulate the thoracic vertebrae directly to the sternum through their own rib cage. The ribs 8,9 and 10 are connected to the sternum through the cartilage that is connected to the seventh-largest cartilage and therefore they are considered to be "false ribs." Ribs 11 and 12 are also false but taken considered as "floating ribs" because they are not attached to the sternum by any cartilage.

\section{The Pectoral and Upper Limbs}

The pectoral band connects the bones of the axial skeleton to the bone and consists of the left and right clavicles and shifts left and right.

Humerus is the bone at the top of the arm. Radius and cubitus are the two bones of the forearm. Ulna is on the medial side of the forearm and forms an articulation with the humerus on the elbow.

The bones of the lower arms form a joint at the wrist with the carpian bones, a group of eight small bones, which adds more flexibility to the wrist. The carpal bones are connected to the five metacarpals that form the bones of the hand and are each connected to one finger. Each finger has three bones known as phalange, except for the thumb, which has only two phalanxes.

\section{The Pelvis and Lower Limbs}

Formed from the left and right hip bones, the pelvic belt connects the bones of the lower limbs (legs) to the axial skeleton.

The femur is the largest bone in the body and the only bone in the thigh region. The blade bone is special because it is one of the few bones that are not present at birth. Rotula is formed in early childhood to support the knee for walking.

Tibia and the pen are the bones of the calf. The tibia is much larger than the toothpick and supports almost the entire weight of the body. Peroneal is mainly a point of attachment of muscles and helps maintain balance. The tibia and the pillow form the ankle joint with the talus, one of the seven tarsal bones in the leg. 
Tarsal bones are a group of seven small bones that form the posterior end of the foot and the heel. Tarsians form the joints with the five long legs of the foot. Each of the metatarsians forms a joint with a set of phalanxes in their toes. As with the hand, each finger has three phalanxes, except for the thumb that has only two.

Microscopic bone structure: The skeleton represents about $30-40 \%$ of the body weight of an adult. The skeleton table is made up of lifeless bone matrix and several small bone cells. Approximately half of the bone matrix mass is water, while the other half is made up of collagen proteins and solid calcium carbonate and calcium phosphate crystals. Bone cells are found on the edges and in the small cavities inside the bone matrix. Although these cells make up little of the total bone mass, they have many important roles in the functions of the bone system. Bone cells allow bones to:

- Grow and develop

- Repair after an accident and daily wear

- Break down to release the stored minerals

Bone types: All body bones can be divided into five types: long, short, flat, irregular and sesame.

Long: Long bones are the main bones of the limbs. Long bones grow more than other bone classes throughout childhood and are responsible for adult height growth. A medullar tubular cavity is found in the center of the long bones and serves as a bone marrow storage area. Examples of long bones include femur, tibia, peroneum, metatarsal and phalange.

Short: Short bones are as long as they are long and are often cubic or round in shape. The carpal bones of the hand and the tarsal bones of the foot are examples of short bones.

Plate: Flat bones vary greatly in size and shape, but they have the common feature, namely to be very thin. Because they are thin, flat bones do not have a medullary cavity like long bones. The frontal, parietal, occipital bones of the skull, along with the hips of the hips and the ribs, are all examples of flat bones.

Irregular: Irregular bones have a shape that does not fit in long, short, or flat bone patterns. Vertebrae, sacrum, spine coccyx and the sphenoid, etmoid and zygomatic bone of the skull are all irregular bones.

Sesamoid: The sesame bones are formed after birth within the tendons that pass by the joints. The sesamoid bones grow to protect the tension tendon and strain on the joints. They rotate the carpian bone, they are the only sesame bones that are considered to be part of the 206 bones of the body. Other sesamoid bones can form in the joints of the hands and feet, but are not present in all people.

\section{Parts of the Bones}

Long body bones contain more distinct regions, due to the way they develop. At birth, each long bone consists of three individual bones, separated by hyaline cartilage. Each final bone is called the epiphysis, while the middle bone is called diaphysis. The epiphysis and diaphysis grow together, eventually merging into one bone. The region of growth and eventual fusion between epiphysis and diaphysis is called metaphysis.

Looking at a cross-sectional bone, there are several distinct stratified regions that make up the bone. The bone is covered with a thin layer of connective tissue, irregular and dense, called periost. The Periosta contains many powerful collagen fibers that are used to firmly anchor tendons and muscles to the bone for movement. Stem cells and osteoblast cells in the periosteum are involved in bone growth and repair, damaged due to excess stress or accidents. Blood vessels present in the periosteum provide energy to the cells on the bone surface. Periotype also contains many nerve endings to give bone sensitivity to pain when it is injured.

\section{Joints}

A joint is a point of contact between the bones, between a bone and the cartilage, or between a bone and a tooth. Synovial joints are the most common type of joints and offer a small gap between the bones. This gap allows freedom of movement and space for synovial fluid to lubricate the joint. There are fibrous joints in which the bones are very well joined and there is no bit of movement between the bones. The fibrous joints also keep the teeth firmly in place. Finally, the cartilage joints are formed where the bone meets the cartilage, or if there is a layer of cartilage between two bones. These joints provide a small amount of flexibility due to the consistent, cartilage-like gel.

\section{Physiology of the Bone System}

Support and protection: The main function of the bone system is to form a solid frame that supports and protects body organs and anchors skeletal muscles. Axial skeletal bones act like a hard shell to protect internal organs such as the brain and heart from damage caused by external forces. The bones of the appendicular skeleton provide support and flexibility in the joints and anchor the muscles that move the limbs.

Movement: The bones of the bone system act as fixation points for the muscles of the body skeleton. Almost every skeletal muscle acts by pulling two or more bones either closer to each other or removing them. The joints act as pivot points for bone movement.

Hematopoiesis: Red bone marrow produces red and white blood cells in a process known as hematopoiesis. Red bone marrow is found in the empty space inside the bones known as the medullary cavity. Children tend to have more 
red bone marrow compared to their body size than adults because of the constant growth and development of their body. Part of the red bone marrow decreases at the end of puberty and is replaced by the yellow bone marrow.

Storage: The bone system stores many different types of essential substances to facilitate body growth and repair. The cell matrix of the bone system acts just like our calcium bank by storing and releasing calcium calcium in the blood as much as necessary. Appropriate levels of calcium ions in the blood are essential for proper functioning of the nervous and muscular system. Bone cells also release osteocalcin, a hormone that helps regulate blood sugar and fat deposits. A yellow bone marrow inside the long tubular bones is used to store energy in the form of lipids.

Growth and development: The skeleton begins to form earlier in fetal development as a flexible skeleton made of hyaline cartilage and fibrous connective tissue, dense and irregular. These tissues act like a soft frame for the bone skeleton to replace them. Once development progresses, blood vessels begin to grow in the soft fetal skeleton, bringing stem cells and nutrients to bone growth. Bone tissue slowly replaces cartilage and fibrous tissue through a process called calcification. At birth, a newborn skeleton has more than 300 bones. With its growth, some of these bones will merge between them, leaving the adult with only 206 bones.

The bones need to be built and then permanently restored to keep them functioning properly. Considering the multiple bone functions, their vitality is essential both to maintain the body and move it and to maintain its health and vigor. When most bones begin to age and have no vital function, the man also begins to age, lose water, minerals, electrolytes, energy, food. We can firmly affirm that healthy bones maintain an excellent health of the human body. All of the bones in the young have the role of deposit, water, electrolyte, minerals, energy, substances necessary for the growth and repair of human cells and organs, a part (red marrow) that permanently produces the vital blood for the organism with the three vital cell types: red (body oxygenation), white (which defends the body) and platelets (it clogs the blood when a wound appears). More recently, it is also known that the red marrow is responsible for the stem cells production, cells which are so necessary to the body because they can adapt to anywhere in the body in any organ, rapidly generating the various types of cells needed. In the bones of the young and most of the adult, all these functionalities appear, so that when an accident requires a human operation it is good to resort to mild and specialized interventions so that the bone in question can quickly recover all features. Otherwise, the body of that person has a major future health and integrity problem, as is the case with older people or those with serious bone diseases (Roger, 2015; Benchea et al.,
1976; McCracken et al., 2000; Pittaccio et al., 2015; Viscuso and Pittaccio, 2012; Priadko et al., 2017; Nikolaev et al., 2008; Yang et al., 2013; Van Humbeeck, 2010; Otsuka and Ren, 1999; Otsuka et al., 1971; Velázquez and Pissaloux, 2012; Melton and Mercier, 1980; Knowles and Smith, 1981; Miyazaki et al., 1984; Lahoz and Puértolas, 2004; Matsumoto et al., 1987; Šittner et al., 2014; Duerig, 1990; Naresh et al 2016; Ziólkowski, 2012; Shaw et al., 2008; Aversa et al., 2018; 2017 a-c, 2016 a-i; 2009; Mirsayar et al., 2017; Petrescu et al., 2015, 2016 a-c; Petrescu and Calautit, 2016 a-b; Kus and Breczko, 2010; Otsuka et al., 1976, Yang and Wayman a and b 1992; Harrison and Hodgson, 1975; Hanlon et al., 1967; Huang et al., 2003; Sofla et al., 2008; Tamburrino, 2016; Apicella et al., 2009-2011; 2015; Gramanzini et al., 2016; Kummer, 1986; Perillo et al., 2010; Oh and Harris, 1976; Gottesman and Hashin, 1980; Ashman et al., 1984; Dalstyra et al., 1993; Burnstein et al., 1976; Carter and Hayes, 1977; Gramanzini et al., 2016; Perillo et al., 2010; Sorrentino et al., 2009; 2007; Beaupre et al., 1985; Reilly and Burstein, 1974; Reilly and Burstein, 1975, Huiskes et al., 1987; Taylor et al., 2007; Rohlmann et al., 1982; Mirsayar and Park, 2016; Mazaheri et al., 2016; Kumar et al., 2016; Annunziata et al. 2006; Gottesman and Hashin, 1980; Huiskes et al., 1987; Taylor et al., 2007; Weinans et al., 1992; Mullender and Huiskes, 1995).

\section{Materials and Methods}

The bone is the basic element of the vertebrate skeleton, characterized by its rugged, solid and resilient structure. The longest bone is the femur of the foot, usually over $50 \mathrm{~cm}$ and the small one is the "snout" in the ear. Between them, the bones bind through the joints and are mobilized by the muscles.

The number of bones decreases in humans by merging, with age, from 350 to a newborn to 206 in an adult. Besides, bone resistance is incredible. A 1centimeter bone cube would be able to support $1,733 \mathrm{~kg}$, the weight of an adult male hippopotamus.

- Bone composition:

- The bone consists of $20 \%$ water and $80 \%$ dry residue. It is made up of a solid organic matrix that is strengthened by deposits of calcium salts.

- Organic bone matrix:

- It is composed of $90-95 \%$ collagen fibers and the rest is a homogeneous environment called fundamental subsonic, together constituting the ossin. The collagen fibers extend first along the lines of the force and give the bone its high voltageresistant.

- Mineral salts:

- In particular calcium phosphate (CaPO4) and the most important crystalline substance is hydroxyapatite (Ca5 (PO4) 3OH). 
- Metabolic processes similar to the other organs occur in the bones. A metabolic particularity is the great affinity of the basic substance for mineral salts.

- Bone structure:

- The bone is made up of 2 types of tissue

Compact bone tissue: The toughest tissue of the human body. The middle part of the long bone, called bone or diaphysis. On the outside there is a membrane, called periost, whose bone increases in thickness. Within the diaphysis we have a channel that runs through its length, called the medullary canal where the hematogenous marrow plays a role in the production of figurative blood (erythrocytes, leukocytes, platelets). It is worth mentioning that in the children all the bones produce this marrow and will have a red color, in the adult only the bones will be yellow and yellow and in the elderly will be gray-gray and will be dysfunctional.

Spongy bone tissue: A relatively light, less durable and resistant structure. Extremes of the long bone (also called tubular bone), called epiphyses. They are made up of $95 \%$ spongy bone tissue on the inside and 5\% compact outer tissue. Between epiphysis and diaphysis is metaphysis, or epiphyseal-diaphysiular growth cartilage, on which long bone grows in length. Growth will be from epiphyses to diaphysis. The epiphyseal joint surface consists of a thin layer of hyaline cartilaginous tissue.
A bone is first produced from a cartilage. The cartilage then slowly transforms into a bone through a complex process. When a baby floats in his mother's womb, the developing organism begins to build its shape and causes the cartilage to do so. Cartilage is a tissue that is not as rough as bones but much more flexible and, in a way, more functional.

A large amount of fetal cartilage starts to turn into bone, the process itself is called ossification. When ossification takes place, cartilage (which does not contain salts or minerals in it) begins to calcify; that is, the layers of calcium and phosphate salts begin to accumulate on the cells of the cartilage slowly. These cells, surrounded by more and more minerals, aging and dying. This leaves some small pockets of separation in the modified cartilage and small blood vessels grow in these cavities. Now, some specialized cells called osteoblasts start traveling in the developing bone through these blood vessels. These cells produce a substance consisting of collagen fibers and also help in the collection of calcium that is deposited along this fibrous substance (A common analogy for this design is reinforced concrete, which is a network of metal bars coated with concrete mixture).

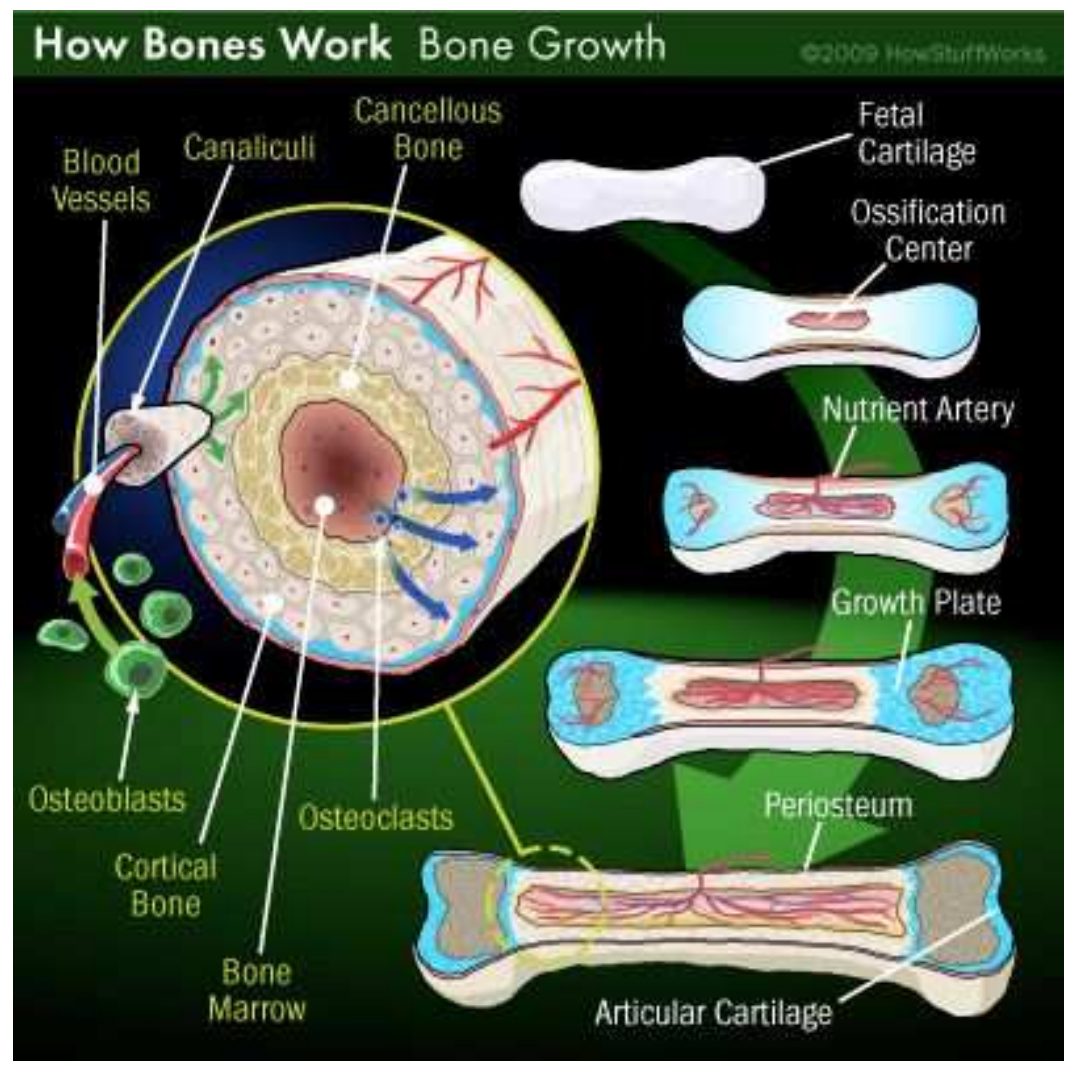

Fig. 1: How does bone grow and develop 


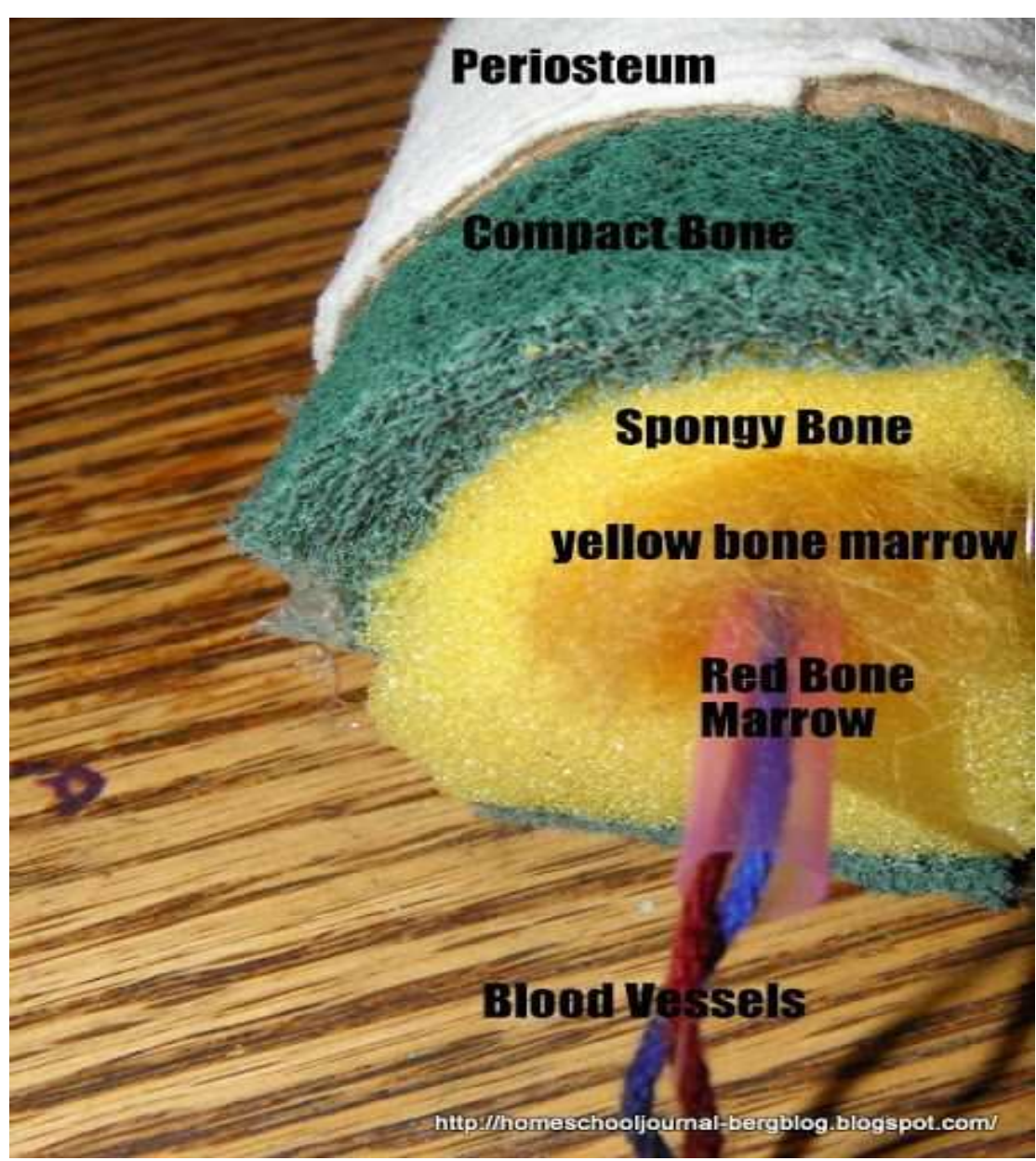

Fig. 2: The structure of a youngster's bone

After a while, osteoblasts become part of the mixture, turning into inferior osteocytes, a retracted version of osteoblasts that continue to sneak but do not distance themselves too much from the blood vessels. This newly formed osteocyte network helps to form the sponge-like network of spongy bone. The oscillating bone is not soft, but looks spongy, meaning that it remains in its construction. These spaces help first of all to transfer the external pressure stress to the entire bone (distribution of external pressure on the entire surface of the bone) and secondly, these spaces also contain the marrow. Channel canals, called canaliculi, run on all calcified bone parts, allowing nutrients, gases, toxins and waste to pass through them (Figs. 1-2).

Developing innovative tissue engineering biomimetic materials based on hydrophilic polymers has been extensively studied in the past decades on their physical, biological and mechanical properties. Although hard in the dry state, such polymers swell in water turning to soft and flexible materials used in several biomedical applications such as ophthalmic lenses, vascular prostheses, drug delivery system and soft-tissue replacement (Apicella et al., 1993). Improved cytocompatibility in terms of cell adhesion and metabolism for IPN of HEMA and PCL were explained in terms of increased surface hydrophobicity leading to improvement of cell adhesion and spreading (Schiraldi et al., 2004). Highly biocompatible novel hybrid materials based on fumed silica and hydrophilic poly-(hydroxy-ethylmethacrylate) (pHEMA) have been developed by the authors (Schiraldi et al., 2004).

The addition of fumed silica is expected to improve the organization of the polymeric network promoting hydrogen bonding of the polymeric chains with the hydrophilic nanoparticles. The resulting nanocomposites consisted in more rigid transparent materials with surprisingly improved mechanical strength and cytocompatibility (Schiraldi et al., 2004) that overcome one of the major drawbacks in hydrogels applications associated with their poor mechanical strength. Early studies confirmed that the nanofilled hybrid composites possess biomimetic and osteoconductive properties that can be useful in the design of mechanically bioactive innovative scaffolding systems for Osteoblast (OB) 
growth (Schiraldi et al., 2004). In healthy conditions, modeling and remodeling collaborate to obtain a correct shape and function of bones. This condition is completely altered when bone is implanted with a rigid prosthesis (Aversa et al., 2009; Sorrentino et al., 2007). Loads on bones cause bone strains that generate signals that some OB cells can detect and respond to.

Threshold ranges of such signals are genetically determined and are involved in the control of modelling and remodelling (Sorrentino et al., 2007; Frost, 1990; Wolff, 1892; Frost, 1964; 1994). Early studies by Wolff (1892) stated that mechanics could determine changes in the architecture of bones (Wolff, 1892). In 1964 Frost expressed mathematically the reactions of the bone tissue to given stimuli to quantitatively assess bone deformations (Frost, 1964). Remodelling processes repair the damage removing and replacing the damaged tissues with new bone. Moreover, overloading (or underloading) alters such phenomenon (Frost, 1994). Mechanically compatible hydrogels as scaffolding materials could increase prosthesis adaptation mechanisms introducing active interfaces that improve implant biomimetics while reproducing cartilage and ligaments bio-mechanical functions. Adaptive properties of bone benefit of use of biomimetic (biomechanically compatible and bioactive) scaffold bio-materials.

\section{Results and Discussion}

Our Biomimetic and Biomechanical approach resulted from a parallel mechanical and physical characterization of new hybrid material coupled to the bio-mechanical Finite Element analysis of the biological system investigated (implanted bones). The mechanics of the "in vitro dynamic bender testing apparatus" were designed by using FEA analysis utilising the material properties of the swollen hybrid pHEMA based nanocomposites. Commercial 2-hydroxyethyl methacrylate, was purchased from Sigma-Aldrich Chemicals Co., (St. Louis, MO, USA). Fumed silicon dioxide with a mean diameter of $7 \mathrm{~nm}$ and specific surface area of $300 \mathrm{~m} 2 \cdot \mathrm{g}-1$ was utilized as the bioactive filler. The initiator, $\alpha-\alpha$ ' azoisobutyrronitrile (AIBN), was purchased from Fluka (Milan, Italy). HEMA monomers were mixed with increasing amount of fumed silica ( 4 to $30 \%$ by volume), according to the procedures described in a previous work. The resin was poured in 10 $\mathrm{mm}$ diameter cylindrical moulds, polymerized in a forced air circulation oven set at $60^{\circ} \mathrm{C}$ for $24 \mathrm{hrs}$ and finally postcured at $90^{\circ} \mathrm{C}$ for $1 \mathrm{~h}$.

The cylindrical samples were used for the water and isotonic saline $(0.15 \mathrm{M} \mathrm{NaCl})$ water solution sorption and swelling experiments. The solution uptakes were determined at equilibrium by gravimetric measurements in a $0.1 \mathrm{mg}$ Mettler Toledo balance (Milan, Italy).

The advancing swelling fronts in the anomalous Case II (Apicella and Hopfenberg, 1982) of the samples were monitored measuring the thickness of the un-swollen residual glassy core as a function of time. The equilibrium sorption and swelling experiments were performed at $37^{\circ} \mathrm{C}$ (thermostatic water bath) until constant weight up-take was monitored $(100 \mathrm{~h})$.

Finite Element Analysis (FEA) on models of the Titanium implanted bones (human mandible segment) and of the in vitro bender set-up was performed according to the following procedures. Implanted bone (human mandible section) the solid models were generated using Solidwork 2007 software. Titanium implant and the surrounding part of a mandibular cortical and cancellous bone were modelled. The average anatomical dimensions of the maxillary bone were generated according to literature data (Schwartz-Dabney, 2003) as a cancellous core surrounded by $2.0 \mathrm{~mm}$-thick cortical bone. The FE model was obtained by importing the solid models into ANSYS rel. 9.0 FEM software (Ansys Inc. Houston) using IGES format. The volumes were meshed with eight nodes brick with 3 degree of freedom per node, resulting in a 3D FE model made up of 31,240 elements and 35,841 nodes. The model was constrained at the top surface of the maxillary bone. Accuracy of the model was checked by convergence tests (Sorrentino et al., 2007).

The geometry of the piezoelectric bender has been measured on the commercial product (see section 2.5) and transferred to the FE environment according to the procedures described for the implanted bone. A $3 \mathrm{~mm}$ thickness symmetrical layers of rubber hydrogel were modelled at the two piezoelectric bender surfaces (simulating a thick coating of our swollen pHEMA based hybrid composite). Orthotropic assumption for cortical bone was adopted while the cancellous bone was considered as isotropic linear materials. The Young's modulus and Poisson's ratio of isotropic materials used in the models of the Titanium implanted bone and piezoelectric bender are shown in Table 1 (Apicella and Aversa, 2012).

Table 1: Isotropic mechanical properties of materials

\begin{tabular}{lll}
\hline & Young's modulus & Poisson's ratio \\
\hline Cancellous bone & $0.91(\mathrm{GPa})$ & 0.30 \\
Titanium & $110(\mathrm{GPa})$ & 0.30 \\
Piezoelectric ceramic & $400(\mathrm{GPa})$ & 0.15 \\
Swollen pHEMA Hybrid nanocomposite & $5(\mathrm{MPa})$ & 0.48 \\
\hline
\end{tabular}


Table 2: Orthotropic constants adopted for the cortical bone on the buccal and palatal sides, respectively

\begin{tabular}{|c|c|c|c|c|c|c|c|c|c|c|}
\hline & Max stiff. $^{\circ}$ & E1 & E2 & E3 & G12 & G31 & G23 & 12 & 31 & 23 \\
\hline Facial & 39.9 & 11 & 15 & 18 & 4.5 & 4.7 & 5.7 & 0.21 & 0.25 & 0.42 \\
\hline Buccal & 4.4 & 12 & 18 & 19 & 4.9 & 4.9 & 5.1 & 0.16 & 0.31 & 0.43 \\
\hline
\end{tabular}

Cortical bone was divided into two sites, one on the buccal side and one on the palatal side according to the mechanical characterization reported for a dentate mandible. Each area has its own orthotropic constants values and orientation of the maximum stiffness direction, the directions of the maximum stiffness is referred to the occlusal plane. $\mathrm{E}$ and $\mathrm{G}$ are expressed in $\mathrm{GPa}$. Direction of maximum stiffness are referred to the global coordinate system. Orthotropic elastic constants and orientation for buccal and palatal sides of cortical bone are reported in Table 2.

Local orientation of the maximum stiffness (E3) and the other two orthogonal stiffness directions (E1, E2) have been reproduced dividing the shell of external elements (compact bone structure) in orientation sites according to the proposed experimental mechanical characterization. The orientation of the maximum stiffness has been reproduced for each site by defining a local coordinate system and by orienting the site's elements coordinate systems accordingly.

The maximum stiffness (E3) directions in degree referred to the occlusal plane on buccal and palatal side are reported in Table 2. E1 direction is normal to the cortical surface.

Shear elastic modulus measurement on dry and swollen p-HEMA Hybrid nanocomposites were performed using a METTLERTOLEDO (Zurich, Switzerland) dynamical mechanical tester operating in shear mode (DMA). The elastic and viscous components of the shear modulus were measured under constant frequency loading in isothermal condition. The samples were dried under vacuum at a $60^{\circ} \mathrm{C}$ for $24 \mathrm{~h}$ before testing. In the shear test mode, the $10 \mathrm{~mm}$ diameter and 2 $\mathrm{mm}$ thickness sample disks are placed between three steel plates forming a symmetrical sandwich. An isothermal scan at $37^{\circ} \mathrm{C}$ in a dry Nitrogen purged environment was performed. The deformation control was set to $10 \mu \mathrm{m}$ and a force limitation of $0,9 \mathrm{~N}$ was applied at an oscillating frequency of $10 \mathrm{~Hz}$.

About $57 \mathrm{~mm}$ piezoelectric benders (Quick-Mount 503, PIEZO SYSTEMS, INC. Woburn, MA USA) were used to build the oscillating dynamic scaffold supports. A proprietary software and electronic apparatus was used to drive oscillating output voltage exit $(0-100 \mathrm{~V})$. The deformations at the bender surface were monitored by acquisition data software (System 4000 with 20 input channels by Vishay Measurements Group Inc., NC, USA) at 2 points/s. The bender operates with $\max$ displacement of $1.0 \mathrm{~mm}$.

\section{In Vivo Osteointegration Tests}

Two implants for each rabbit tibia, in 6 rabbits (total of 24 implants in New Zealand White rabbits); each rabbit has been implanted with 2 implants coated with the nanostructured hybrid biomaterial on the right tibia and 2 control implants in the left tibia.

Micro Computer Tomography with resolution 1 voxel $=15$ cubic micron has been performed on the explanted tibiae after 1 week, 1, 2, 4 and 6 months.

BV/TV (Bone Volume/Total Volume), BS/TV (Bone Surface), TbTh (Trabecular Thickness), TbSp (Trabecular Separation), TbN (Trabecular Number) have been used to evaluate the Total BIA (bone implant apposition).

The aim of our research was to develop a biomimetical/biomechanical approach for the design of the experimental dynamic procedures (biologicalmechanical stimulus) finalized to favour adaptive directionally organized OB growth in vitro scaffold mineralization. In order to achieve this result, both a proper biomimetic scaffolding material and an externally driven mechanically straining apparatus have had to be designed.

The biomimetic characteristic of our hybrid materials have been investigated both for mechanical than osteoconductive properties.

\section{Bio-Mimetics: Hybrid Nanocomposites Properties Design}

Physiological bone material behaviour to be mimicked by the bio-active scaffolding material relates to the following aspects:

- Mechanical properties (dry - swollen)

- Bioactivity (in vivo tests)

- In order to define the proper nanofiller/polymer ratio of potentially idoneous the hybrid nanocomposites the objective properties requirements are

- Similar to bone rigidity (Elastic Modulus 6-15 GPa and shear modulus G 2-5 GPa) when dry

- Similar to cartilage and ligament flexibility (Halpin and Kardos, 1976) (high deformability - Elastic modulus 2-20 MPa) when swollen.

\section{Mechanical Properties}

The dry Hybrid pHEMA nanocomposites with compositions ranging from 4 to $30 \%$ by volume of nano silica were isothermally shear tested in a Dynamic Mechanical Analyser operating at $10 \mathrm{~Hz}$ and at $37^{\circ} \mathrm{C}$. 


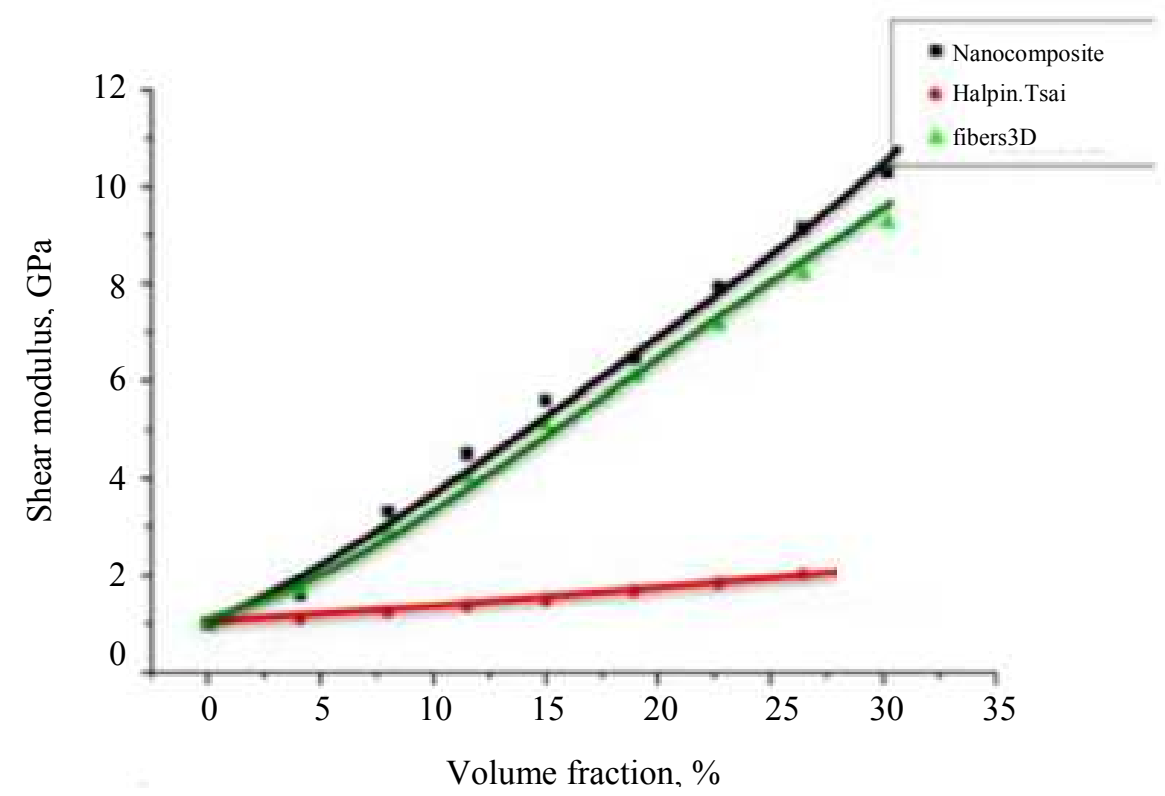

Fig. 3: Hybrid shear moduli (black), Halpin-Tsai (red) and 3D fibers composite (silica glass fibers mat) (green)

The samples showed a predominantly elastic behavior (the viscous component was negligible for all compositions). The values of the measured Shear moduli are reported in Fig. 3. The compositional dependence of the shear modulus of the nanocomposites does not follow the ordinary Halpin-Tsai relationship utilized to describe the elastic properties of particulate composites (red line), while resembles to that of a 3D oriented fibre mat (green line in Fig. 3), indicating the formation of a continuous hybrid ceramic-polymeric structure. Shear moduli comparable to those of the cortical bone have been measured for nano-silica volumetric fractions ranging from 4 to $12 \%$. A volume fraction of $5 \%$ has been then chosen for the in vivo osteointegration tests and for the FEA simulations.

The 5\% hybrid nanocomposites dramatically swell in water solutions picking up $50 \%$ of its dry weight and reducing its shear modulus to 2-3 $\mathrm{MPa}$ (measured in the DMA). Such phenomenon is associated with the water induced polymer plasticization that reduces the polymer glass transition temperature below the test temperature.

This behavior has been investigated in a physiological isotonic $0.15 \mathrm{M} \mathrm{NaCl}$ solution held at $37^{\circ} \mathrm{C}$ for the $5 \%$ volume fraction sample both for equilibrium and swelling kinetic. Once exposed to the water solution, the initially dry and glassy pHEMA composite starts to swell showing a clear front dividing the rubber swollen external portion and the unaffected glassy core. This glassy core thickness progressively reduces the swollen front advance through the sample (upper part of Fig. 4). A measure of the swelling kinetic is given by the rate of reduction of the glassy core as a function of the time (lower diagram in Fig. 4). The swelling front advances at a constant rate: this behavior is characteristic of a limiting relaxation controlled sorption mechanism indicated as "Case II sorption" (Apicella et al., 1993; Schiraldi et al. 2004; Aversa et al., Sorrentino et al., 2007; Frost, 1990; Wolff, 1892; Frost, 1964; 1994; Apicella and Hopfenberg, 1982). At equilibrium, when swelling fronts meet, a $14.5 \%$ increase of the sample diameter has been measured (about $50 \%$ of volume increase).

\section{Biomechanics: Adaptive Properties of Bone}

The use of a biocompatible and biomechanically active interface that can be "designed" to reproduce bonecompatible and biomimetic strain distribution is discussed in the present paper (Frost, 1990; 1994) are reported in Fig. 5. There are upper $(>3000 \mu \varepsilon)$ and lower $(<50 \mu \varepsilon)$ strain limits that do not favor healthy bone growth.

The comparison between FEA simulation of physiological strains in coated and uncoated implants and bone volumes in the in rabbit tibiae after two months of in vivo test is reported in Fig. 5. The FEA simulations of the strain distribution reported of the same Fig. 5 have been run on a mandibular bone section that presents comparable to the rabbit tibia mechanical and dimensional characteristics. 


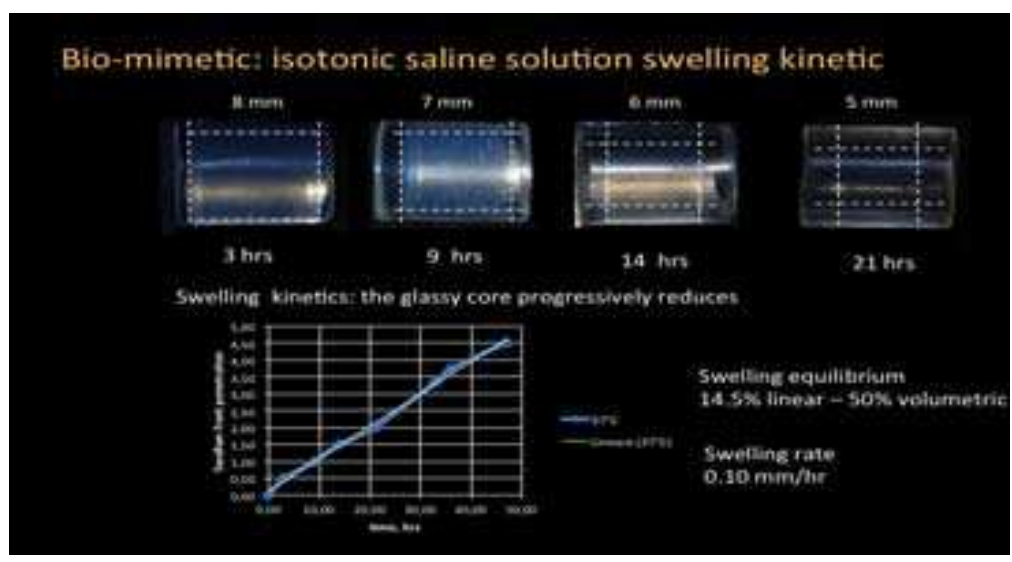

Fig. 4: Swelling kinetics of a $5 \%$ by volume hybrid nanocomposite in $0.15 \mathrm{M} \mathrm{NaCl}$ water solution (isotonic)

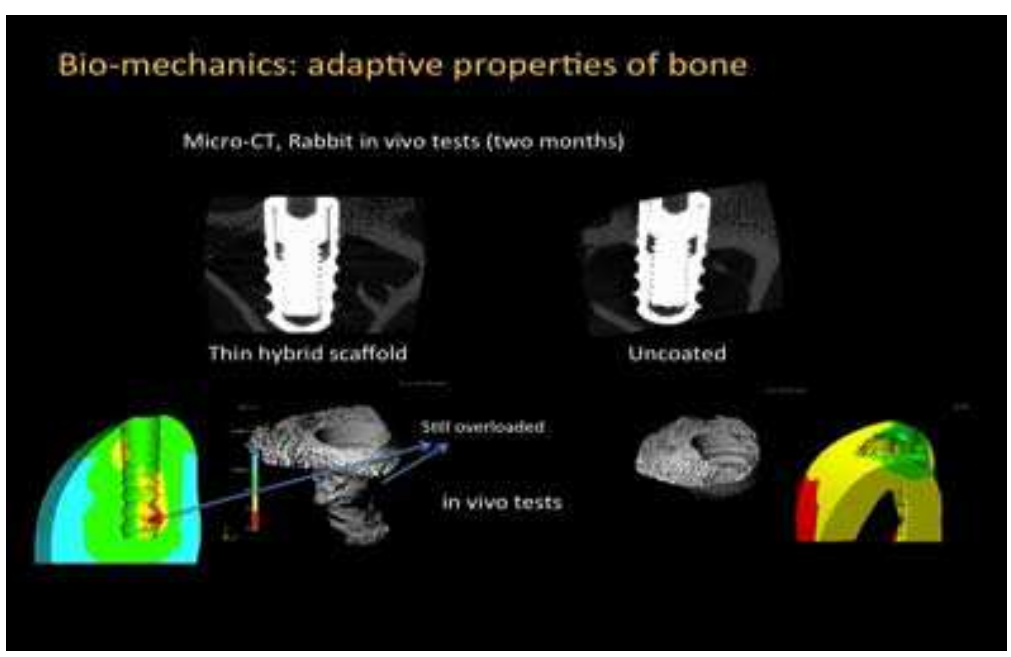

Fig. 5: Osteointegration of Titanium implants with a nanostructured hybrid biomimetic coating (left side) and without (right). MicroCT bone reconstruction and FEA calculated physiological strain distributions are compared

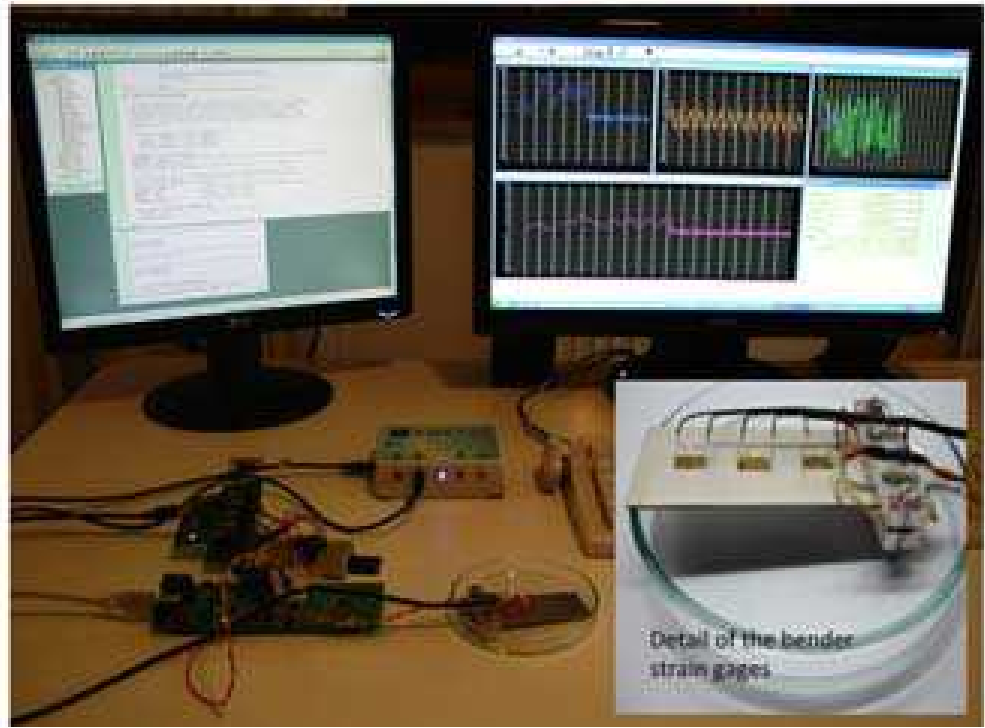

Fig. 6: Piezoelectric bender for dynamic OB cells culture tests: calibration test configuration 
The Micro CT bone reconstructions of the perimplantar areas of the hybrid nanostructured biomaterial coated and of the "as received" implants after two months are compared in Fig. 5: The nanostructured biomaterial coated implant shows a better osteointegration that can be related to the osteoconductivity of the perimplantar biomimetic hybrid coating. The bone implant apposition or bone in growth (Comeron, 1986), which is defined as the percentage of osteointegrated implant length for the biomimetically coated and uncoated implants in the six months in vivo test show a significant improvement of about $100 \%$ increase in the first two months and $30 \%$ after 6 months. The Osteoblast proliferation and bone growth in the implanted tibiae are clearly favored and accelerated by the presence of the hybrid nanostructured coating. The biomechanical approach using the adaptive properties of bone well describes the biomimetic behaviour of the proposed perimplantar hybrid scaffold since it can predict areas of bone resorption (FEA model elements with strains below the physiological lower limits have been removed in the image), as it occurs in the in vivo tests at the neck of the implant (Micro CT reconstruction on the right side of Fig. 5). The proposed biomechanical model can predict areas of bone growth (FEA model and micro CT reconstruction compared in the left side of Fig. 5).

Dynamic factors have been accounted and utilized to design a piezoelectric driven dynamic scaffold deformation apparatus for in vitro adaptive osteoblast cells growth. Biomimetic aspects are investigated by using the osteoconductive hybrid nanocomposites bender thick swollen coating coupled with a FEM modeling of the in vitro bone adaptive growth. The piezoelectric dynamic bender and control system is shown in Fig. 6 .

\section{Conclusion}

It was a biomimetic/biomechanical approach followed in the design of experimental dynamics (biomechanical incentives) for in vitro the scheme of mineralization and ossification using piezoelectric benders. The proposed material is a Nanocomposites Polymer Polymer Polymer Ceramic-Polymer Polymer, Hydroxy-ethyl-methacrylate (pHEMA) audited with nano silica particles ( $4-6 \%$ by volume). This the biomimetic material swells in the presence of physiological solution (when in an aqueous biological environment), collecting up to $50-30 \%$ by weight of water. The mechanical behavior of the glass is comparable to that of the bone, while under swollen rubber conditions it is comparable to cartilage and ligaments.

\section{Acknowledgement}

The Authors acknowledge Liquid Metals Technologies Inc, Ca USA that kindly supplies the samples for the characterization and Dream Laboratory (Virginia Tech, VA, USA).

\section{Funding Information}

This research has been funded by Italian Ministry of University and Research project FIRB Future in Research 2008, project RBFR08T83J.

\section{Author's Contributions}

All the authors contributed equally to prepare, develop and carry out this manuscript.

\section{Ethics}

This article is original and contains unpublished material. Authors declare that are not ethical issues and no conflict of interest that may arise after the publication of this manuscript.

\section{References}

Annunziata, M., R. Aversa, A. Apicella, A. Annunziata and D. Apicella et al., 2006. In vitro biological response to a light-cured composite when used for cementation of composite inlays. Dental Materials, 22: 1081-1085.

Apicella, A. and R. Aversa. 2012. A biomimetic and biomechanical approach for tissue engineering. Proceedings of the International Conference on Biomedical Electronics and Devices. BIODEVICES.

Apicella, A. and H. Hopfenberg, 1982. Water-swelling behavior of an ethylene-vinyl alcohol copolymer in the presence of Sorbed sodium chloride. J. Applied Polymer Sci., 27: 1139-1148.

Schwartz-Dabney, C.L., 2003. Variations in cortical material properties throughout the human dentate mandible. Am. J. Phys. Anthropol., 120: 252-277.

Apicella, D., R. Aversa, E. Ferro, D. Ianniello and A. Apicella, 2010. The importance of cortical bone orthotropicity, maximum stiffness direction and thickness on the reliability of mandible numerical models. J. Biomedical Materials Research - Part B Applied Biomaterials, 93: 150-163.

DOI: 10.1002/jbm.b.31569

Apicella, D., M. Veltri, P. Balleri, A. Apicella and M. Ferrari, 2011. Influence of abutment material on the fracture strength and failure modes of abutmentfixture assemblies when loaded in a bio-faithful simulation. Clinical Oral Implants Res., 22: 182-188: DOI: 10.1111/j.1600-0501.2010.01979.x

Apicella, D., R. Aversa, M. Tatullo, M. Simeone and S. Sayed et al., 2015. Direct restoration modalities of fractured central maxillary incisors: A multi-levels validated finite elements analysis with in vivo strain measurements. Dental Materials, 31: e289-e305. DOI: $10.1016 /$ j.dental.2015.09.016 
Ashman, R.B., S.C. Cowin, W.C. Van Buskirk and J.C. Rice, 1984. A continuous wave technique for the measurement of the elastic properties of cortical bone, J. Biomechanics, 17: 349-361. DOI: 10.1016/0021-9290(84)90029-0

Aversa, R., D. Apicella, L. Perillo, R. Sorrentino and F. Zarone et al., 2009. Non-linear elastic threedimensional finite element analysis on the effect of endocrown material rigidity on alveolar bone remodeling process. Dental Materials, 25: 678-690: DOI: 10.1016/j.dental.2008.10.015

Aversa, R., F.I.T. Petrescu, R.V. Petrescu and A. Apicella, 2016a. Biomimetic FEA bone modeling for customized hybrid biological prostheses development. Am. J. Applied Sci., 13: 1060-1067. DOI: 10.3844/ajassp.2016.1060.1067

Aversa, R., F.I.T., Petrescu, R.V. Petrescu and A. Apicella, 2016b. Biofidel FEA modeling of customized hybrid biological hip joint prostheses, Part I: Biomechanical behavior of implanted femur. Am. J. Biochemistry Biotechnol., 12: 270-276. DOI: 10.3844/ajbbsp.2016.270.276

Aversa, R., F.I.T. Petrescu, R.V.V. Petrescu and A. Apicella, 2016c. Biomimetic finite element analysis bone modeling for customized hybrid biological prostheses development. Am. J. Applied Sci., 13: 1060-1067. DOI: 10.3844/ajassp.2016.1060.1067

Aversa, R., D. Parcesepe, R.V. Petrescu, G. Chen and F.I.T. Petrescu et al., 2016d. Glassy amorphous metal injection molded induced morphological defects. Am. J. Applied Sci., 13: 1476-1482. DOI: 10.3844/ajassp.2016.1476.1482

Aversa, R., R.V. Petrescu, F.I.T. Petrescu and A. Apicella, 2016e. Smart-factory: Optimization and process control of composite centrifuged pipes. Am. J. Applied Sci., 13: 1330-1341.

DOI: 10.3844/ajassp.2016.1330.1341

Aversa, R., F. Tamburrino, R.V. Petrescu, F.I.T. Petrescu and M. Artur et al., $2016 \mathrm{f}$. Biomechanically inspired shape memory effect machines driven by muscle like acting NiTi alloys. Am. J. Applied Sci., 13: 1264-1271. DOI: 10.3844/ajassp.2016.1264.1271

Aversa, R., F.I.T. Petrescu, R.V.V. Petrescu and A. Apicella, 2016g. Flexible stem trabecular prostheses. Am. J. Eng. Applied Sci., 9: 1213-1221. DOI: 10.3844/ajeassp.2016.1213.1221

Aversa, R., R.V.V. Petrescu, A. Antonio and F.I.T. Petrescu, 2016h. Physiologic human fluids and swelling behavior of hydrophilic biocompatible hybrid ceramo-polymeric materials. Am. J. Eng. Applied Sci., 9: 962-972.

DOI: 10.3844 /ajeassp.2016.962.972
Aversa, R., R. Sorrentino and A. Apicella, 2016i. Biomechanically active ceramic-polymeric hybrid scaffolds for tissue engineering. Proceedings of the International Conference on Biological Sciences and Technology (BST 2016), Atlantis Press, pp: 308-318.

Aversa, R., R.V.V. Petrescu, A. Apicella and F.I.T. Petrescu, 2017a. Nano-diamond hybrid materials for structural biomedical application. Am. J. Biochemistry Biotechnology, 13: 34-41.

Aversa, R., D. Parcesepe, R.V. Petrescu, F. Berto and G. Chen et al., 2017b. Processability of bulk metallic glasses. Am. J. Applied Sci., 14: 294-301. DOI: 10.3844/ajassp.2017.294.301

Aversa, R., R.V. Petrescu, A. Apicella and F.I.T. Petrescu, 2017c. Modern transportation and photovoltaic energy for urban ecotourism. Transylvanian Rev. Administrative Sci., 13: 5-20. DOI: $10.24193 /$ tras.SI2017.1

Aversa, R., R.V. Petrescu, F.I.T. Petrescu and A. Apicella, 2018. Nanodiamond for structural biomimetic scaffolds. MSCE, 6: 6-17. DOI: $10.4236 /$ msce. 2018.64002

Beaupre, G.S. and W.C. Hayes, 1985. Finite element analysis of a three dimensional open-celled model for trabecular bone. J. Biomech. Eng., 107: 249-56. PMID: 4046566

Benchea, E. et al., 1976. Comparative study in the cordata series. Didactic Pedagogical Ed., Bucharest.

Burnstein, A., D.T. Reilly and M. Martens, 1976. Aging of bone tissue: Mechanical properties. J. Bone Joint Surgery, 58: 82-86.

Carter, D.R. and W.C. Hayes, 1977. The compressive behavior of bone as a two phase porous structure. J. Bone Joint Surgery, 59A: 954. PMID: 561786

Comeron, H.U., 1986. Six-year results with a microporous-coated metal hip prosthesis. Clin. Orthop., 208: 81-83.

Dalstyra, M., R. Huiskes, A. Odgaard and L. Van Erning, 1993. Mechanical and textural properties of Pelvic Trabecular Bone. J. Biomechanics, 26: 349-361. DOI: 10.1016/0021-9290(93)90014-6

Duerig, T.W., 1990. Engineering aspects of shape memory alloys. Butterworth-Heinemann, London, England.

Frost, H.M., 1990. Skeletal Structural Adaptations to Mechanical Usage (SATMU): 1. Redefining Wolff's law: The bone modeling problem. Anat Rec., 226: 403-13.

Frost, H.M., 1964. Mathematical elements of lamellar bone remodeling. Springfield: C. C Thomas, pp: 22-25.

Frost, H.M., 1994. Wolff's Law and bone's structural adaptation to mechanical usage: an overview for clinicians. Angle Orthod., 64: 175-88.

Gottesman, T. and Z. Hashin, 1980. Analysis of viscoelastic behaviour of bones on the basis of microstructure. J. Biomechanics, 13: 89-96: DOI: 10.1016/0021-9290(80)90182-7 
Gramanzini, M., S. Gargiulo, F. Zarone, R. Megna and A. Apicella et al., 2016. Combined microcomputed tomography, biomechanical and histomorphometric analysis of the peri-implant bone: A pilot study in minipig model. Dental Materials, 32: 794-806.

DOI: $10.1016 /$ j.dental.2016.03.025

Halpin, J.C. and J.L. Kardos, 1976. The Halpin-Tsai equations: A review. Polymer Eng. Sci., 16: 344-352.

Hanlon, J.E., S.R. Butler and R.J. Wasilewski, 1967. Effect of martensitic transformation on the electrical and magnetic properties of NiTi. Trans. Metallurgical Society AIME, 239: 1323-1327.

Harrison, J.D. and D.E. Hodgson, 1975. Use of TiNi in mechanical and electrical connectors, shape memory effects in alloys. Plenum Press, N.Y.

Huang, X., G.J. Ackland and K.M. Rabe, 2003, Crystal structures and shape-memory behaviour of NiTi. Nature Materials, 2: 307-311.

DOI: $10.1038 /$ nmat 884

Huiskes, R., H. Weinans, H.J. Grootenboer, M. Dalstra and B. Fudula et al., 1987. Adaptive bone remodeling theory applied to prosthetic-design analysis. J. Biomech., 20: 1135-1150.

Knowles, K.M. and D.A. Smith, 1981. The crystallography of the martensitic transformation in equiatomic nickeltitanium. Acta Metall., 29: 101-110.

Kumar, A., A. Rathi, J. Singh and N.K. Sharma, 2016. Studies on titanium hip joint implants using finite element simulation. Proceedings World Congress Engineering.

Kummer, B., 1986. Biomechanical principles of the statistics of the hip joint: A critical appraisal of a new theory. Zeitschrift fur Orthopadie und Ihre Grenzgebiete, 124: 179-187.

Kus, K. and T. Breczko, 2010. DSC-investigations of the effect of annealing temperature on the phase transformation behaviour in Ni-Ti Shape Memory Alloy. Materials Physics Mechanics, 9: 75-83.

Lahoz, R. and J.A. Puértolas, 2004. Training and twoway shape memory in NiTi alloys: Influence on thermal parameters. J. Alloys Compounds.

Matsumoto, O., S. Miyazaki, K. Otsuka and H. Tamura, 1987. Crystallography of martensitic transformation in TiNi single crystals. Acta Metall., 35: 2137-2144. DOI: 10.1016/0001-6160(87)90042-3

Mazaheri, M., K. Hassani, A. Karimi and F. Izadi, 2016. Finite element study of composite materials as an alternative for metal hip prothesis using variable load. Materials Focus, 5: 430-435.

Melton, K.N. and O. Mercier, 1980. The mechanical properties of NiTi-based shape memory alloys. Acta Metallurgica.

Mirsayar, M.M., V.A. Joneidi, R.V. Petrescu, F.I.T. Petrescu and F. Berto, 2017. Extended MTSN criterion for fracture analysis of soda lime glass. Eng. Fracture Mechan., 178: 50-59.

DOI: 10.1016/j.engfracmech.2017.04.018
Mirsayar, M.M. and P. Park, 2016. Modified maximum tangential stress criterion for fracture behavior of zirconia/veneer interfaces. J. Mechanical Behavior Biomedical Materials, 59: 236-240.

Miyazaki, S., S. Kimura, K. Otsuka and Y. Suzuki, 1984. The habit plane and transformation strains associated with the martensitic transformation in TiNi single crystals. Scripta Metall., 18: 883-888. DOI: 10.1016/0036-9748(84)90254-0

Mullender, M.G. and R. Huiskes, 1995. A proposal for the regulatory mechanism of Wolff's law. J. Orthop Res., 13: 503-512. DOI: 10.1002/jor.1100130405

Naresh, C., P.S.C. Bose and C.S.P. Rao, 2016, Shape memory alloys: A state of art review. IOP Conf. Mater. Sci. Eng.

McCracken, T., R. Walker and S. Sânza, 2000. New atlas of human anatomy. Aquila Publishing House, Oradea.

Nikolaev, V.I., S.A. Pul'nev, G.A. Malygin, V.V. Shpeizman and S.P. Nikanorov, 2008. Generation and relaxation of reactive stresses in a $\mathrm{Cu}-\mathrm{Al}-\mathrm{Ni}$ shape memory alloy upon cyclic temperature variation in the range 293-800 K. Phys. Solid State, 50: 2170-2174. DOI: 10.1134/S1063783408110279

Oh, I. and W.H. Harris, 1976. Proximal distribution in the loaded femur. J. Bone Joint Surgery. PMID: 624762 .

Otsuka, K., Sawamura T, K. Shimuzu, 1971. Crystal structure and internal defects of equiatomic TiNi martensite. Phys. Stat. Sol. 5a: 457-470.

Otsuka, K. and X. Ren, 1999. Recent developments in the research of shape memory alloys. Intermetallics, 7: 511-528. DOI: 10.1016/S0966-9795(98)00070-3

Otsuka, K., C.M. Wayman, K. Nakay, H. Sakamoto and K. Shimizu, 1976. Superelasticity effects and stressinduced martensitic transformations in $\mathrm{CuAlNi}$ alloys. Acta Metallurgica, 24: 207-226.

Perillo, L., R. Sorrentino, D. Apicella, A. Quaranta and E. Gherlone et al., 2010. Nonlinear visco-elastic finite element analysis of porcelain veneers: A submodelling approach to strain and stress distributions in adhesive and resin cement. J. Adhesive Dentistry, 12: 403-413.

Petrescu, F.I.T., E. Buzea, L. Nănuţ, M. Neacşa and C. Nan, 2015. The role of antioxidants in slowing aging of skin in a human, Analele Univers. Craiova Biologie Horticultura Tehn. Prel. Prod. Agr. Ing. Med., 20: 567-574.

Petrescu, R.V., R. Aversa, A. Apicella, S. Li and G. Chen et al., 2016a. Something about electron dimension. Am. J. Applied Sci., 13: 1272-1276.

Petrescu, R.V., R. Aversa, A. Apicella, F. Berto and S. Li et al., 2016b. Ecosphere protection through green energy. Am. J. Applied Sci., 13: 1027-1032. 
Petrescu, F.I.T., A. Apicella, R.V. Petrescu, S.P. Kozaitis and R.B. Bucinell et al., 2016c. Environmental protection through nuclear energy. Am. J. Applied Sci., 13: 941-946.

Petrescu, F.I.T. and J.K. Calautit, 2016a. About nano fusion and dynamic fusion, Am. J. Applied Sci., 13: 261-266.

Petrescu, F.I.T. and J.K. Calautit, 2016b. About the light dimensions. Am. J. Applied Sci., 13: 321-325.

Pittaccio, S., L. Garavaglia, C. Ceriotti and F. Passaretti, 2015. Applications of shape memory alloys for neurology and neuromuscular rehabilitation. J. Funct. Biomater., 6: 328-344. DOI: $10.3390 / \mathrm{jfb} 6020328$

Priadko, A.I., V.I. Nikolaev, S.A. Pulnev, S.I. Stepanov and A.V. Rogov et al., 2017. Shape memory cu-alni single crystals for application in rotary actuators. Materials Physics Mechanics, 32: 83-87.

Reilly, D.T. and A.H. Burnestain, 1975. The elastic and ultimate properties of compact bone tissue. J. Biomechanics, 8: 393-405. DOI: 10.1016/0021-9290(75)90075-5

Reilly, D.T. and A.H. Burstein, 1974. The mechanical properties of cortical bone. J. Bone Joint Surgery, 56: 1001-1021.

Roger, J., 2015. Leonardo da vinci: Anatomist. British J. General Practice, 62.599: 319.

Rohlmann, A., U. Mossner, G. Bergmann and R. Kolbel, 1982. Finite element analysis and experimental investigations of stresses in a femur. J. Biomed. Eng. DOI: 10.1016/0141-5425(82)90009-7

Schiraldi, C., A. D'Apicella, R. Aversa and M. De Rosa, 2004. Development of hybrid materials based on hydroxyethylmethacrylate as supports for improving cell adhesion and proliferation. Biomaterials, 25: 3645-3653. DOI: $10.1016 /$ j.biomaterials.2003.10.059

Shaw, J.A., C.B. Churchill and M.A. Iadicola, 2008. Tips and tricks for characterizing shape memory alloy wire: Part 1 - Differential Scanning Calorimetry and basic phenomena. Society Experimental Mechanics. DOI: $10.1111 / \mathrm{j} .1747-1567.2008 .00410 . \mathrm{x}$

Šittner, P., L. Heller, Pilch, C. Curfs and A. Thiery et al., 2014. Young's modulus of austenite and martensite phases in superelastic NiTi wires. J. Materials Engineering Performance, 23: 2303-2314. DOI: $10.1007 / \mathrm{s} 11665-014-0976-\mathrm{x}$

Sofla, A.Y.N., D.M. Elzey and H.N.G. Wadley, 2008. Two-way antagonistic shape actuation based on the one-way shape memory effect. J. Intelligent Material Systems Structures, 19: 1017-1027.
Sorrentino, R., D. Apicella, C. Riccio, E. Gherlone and F. Zarone et al., 2009. Nonlinear visco-elastic finite element analysis of different porcelain veneers configuration. J. Biomedical Materials Res. - Part B Applied Biomaterials, 91: 727-736. DOI: $10.1002 / \mathrm{jbm} . b .31449$

Sorrentino, R., R. Aversa, V. Ferro, T. Auriemma and F. Zarone et al., 2007. Three-dimensional finite element analysis of strain and stress distributions in endodontically treated maxillary central incisors restored with different post, core and crown materials. Dent Mater., 23: 983-93. DOI: $10.1016 /$ j.dental.2006.08.006

Tamburrino, F., 2016. Advanced manufacturing for novel materials in industrial design applications, development of a smart and adaptive shadow system using SMAs. Ph.D. Thesis, Italy.

Taylor, D., J.G. Hazenberg and T.C. Lee, 2007. Living with cracks: Damage and repair in human bone. Nat. Mater., 6: 263-268.

Van Humbeeck, J., 2010. Introduction to shape memory alloys. Proceedings of the School and Symposium on Smart Structural Systems Technologies (S3T' 10), Porto, Portugal, pp: 3-23.

Velázquez, R. and E.E. Pissaloux, 2012, Modelling and temperature control of Shape Memory Alloys with fast electrical heating. Int. J. Mechanics Control.

Viscuso, S. and S. Pittaccio, 2012. Design and implementation of a portable a magnetic shape memory rotary actuator. J. Intell. Mater. Syst. Struct., 24: 454-472.

Weinans, H., R. Huiskes and H.J. Grootenboer, 1992. The behavior of adaptive bone remodeling simulation models. J. Biomech, 25: 1425-1441. PMID: 1491020

Wolff, J.D.G., 1892. Transformation der Knochen. Berlin: A Hirschwald.

Yang, J.H. and C.M. Wayman, 1992. Self-accomodation and shape memory mechanism of $\varepsilon$-martensite-I. Experimental observations. Materials Characterization, 28: 23-35.

Yang, H.Z., X.G. Duan and H. Deng, 2013. A study on the force distribution for artificial antagonistic muscles. Mechanics Materials, 278-280: 105-110.

Ziólkowski, A., 2012. On analysis of DSC curves for characterization of intrinsic properties of NiTi shape memory alloys. Proceedings of the 12th International Symposium on Physics of Materials, Sept. 4-8, Prague. 